\title{
Análise de processos de ensino-aprendizagem de temas nutrição em salas de espera
}

\author{
Paulo César Gomes \\ Doutor em Educação para a Ciência, Docente do Departamento de Educação, Instituto de Biociências, \\ Universidade Estadual Paulista Júlio de Mesquita Filho - Campus Botucatu. \\ $\bowtie$ pcgomes21@ibb.unesp.br \\ Sílvia Justina Papini \\ Doutora em Ciências dos Alimentos, Docente da Faculdade de Medicina de Botucatu, \\ Universidade Estadual Paulista Júlio de Mesquita Filho.

\section{Luiza Cristina Godim Domingues Dias} \\ Doutorado em Fisiopatologia em Clínica Médica, Docente do Departamento de Educação, Instituto de \\ Biociências, Universidade Estadual Paulista Júlio de Mesquita Filho - Campus Botucatu.
}

Recebido em 7 de dezembro de 2017

Aceito em 31 de maio de 2018

\section{Resumo:}

Este estudo investigou a prática educativa de uma graduanda do último ano do curso de Nutrição no espaço de educação não formal denominado na literatura por 'Sala de Espera' em distintas Unidades de Estratégia de Saúde da Família. Buscou-se investigar a atuação da participante e como procedia à delimitação de objetivos, estratégias de ensino e de avaliação em três distintas atividades de interações com os pacientes. Além de verificar se a ferramenta Avaliação Funcional Descritiva, largamente utilizada na Análise Aplicada do Comportamento, poderia fornecer elementos para que a própria participante modificasse sua prática educativa durante a interação com os pacientes em situação de espera. Os resultados evidenciaram que a participante executou modificações na maneira como passou a descrever seus objetivos, estratégias de ensino e medidas de avaliação dos pacientes. A participante também promoveu alterações no modo como conduziu as Salas de Espera, isto é, em seu repertório de ensino e como passou a "interpretar", isto é, relatar processos de ensino-aprendizagem decorrentes, além de ter promovido mudanças significativas na maneira como conduziu as interações com os pacientes em situação de espera.

Palavras-chave: Avaliação Funcional Descritiva, Sala de espera, Educação não formal.

\section{Analysis of teaching learning strategies in the waiting room}

\begin{abstract}
:
This study investigates the educational practice of a undergraduate student of the final year of nutrition course. She worked in Waiting Room in different units of the Family Health Strategy. We sought to investigate the role of participant in the delimitation of objectives, teaching strategies and assessment activities into three distinct interactions with patients. Besides checking the Descriptive Functional Assessment tool, widely used in Applied Behavior Analysis, could provide elements for the participant to modify their own educational practice during interaction with patients in the waiting situation. It draws on qualitative data from a study of processes of teaching and learning in Nonformal learning settings. The results showed that teaching-learning processes were modified and sought to meet the demands of patients in the waiting room. It is worth noting that student promoted
\end{abstract}


significant changes in own performance throughout this investigation. This article evidenced the importance of work of nutritionist in waiting room in the different health services.

Keywords: Functional descriptive assessment, Waiting room, Nonformal settings.

\section{Análisis de procedimientos de enseñanza-aprendizaje de temas nutrición en salas de espera}

\section{Resumen:}

Este estudio investigó la práctica educativa de una graduada del último año del curso de Nutrición en el espacio de educación no formal denominado en la literatura por 'Sala de Espera' en distintas Unidades de Estrategia de Salud de la Familia. Se buscó investigar la actuación de la participante y cómo procedía a la delimitación de objetivos, estrategias de enseñanza y de evaluación en tres distintas actividades de interacciones con los pacientes. Además de verificar si la herramienta Evaluación funcional descriptiva, ampliamente utilizada en el Análisis Aplicado del Comportamiento, podría proporcionar elementos para que la propia participante modificara su práctica educativa durante la interacción con los pacientes en situación de espera. Los resultados evidenciaron que la participante ejecutó modificaciones en la manera como pasó a describir sus objetivos, estrategias de enseñanza y medidas de evaluación de los pacientes. La participante también promovió cambios en el modo en que condujo las Salas de Espera, es decir, en su repertorio de enseñanza y cómo pasó a interpretar procesos de enseñanza-aprendizaje resultantes, además de haber promovido cambios significativos en la manera como condujo las interacciones con los pacientes en situación de espera. Palabras clave: Evaluación Funcional Descriptiva, Sala de espera, Educación no formal.

\section{INTRODUÇÃO}

O local Sala de Espera assume uma posição sui generis na condição de espaço de educação não formal: justamente por agregar pacientes com problemas de saúde semelhantes ou não, que aguardam atendimento médico, assistem a televisão, falam ao celular e com outros pacientes, transitam com carrinho de bebê e, geralmente, aguardam atendimento onde há fluxo de pessoas (TEIXEIRA, VELOSO, 2006). A cacofonia do local, geralmente, é interrompida pela chamada da senha ou do nome do próximo paciente da fila a ser atendido. É neste lugar, aparentemente caótico, que os profissionais da saúde ensinam conteúdos com temáticas diversas. No ensino destes temas existe a intencionalidade, o planejamento e a organização das ações ali desenvolvidas, além da estruturação dos processos de aprendizagem (GOHN, 2008, p.101).

O trabalho de Educação em Saúde realizado nas salas de espera está fora do marco oficial da Educação Formal - fora da Escola e fora do currículo - e tem por objetivo central atender a grupos específicos (idosos, gestantes, nutrizes, crianças, diabéticos, etc.) ou pacientes em geral. Nesta condição, este trabalho integra a chamada Educação Não-Formal 
(ENF), que é entendida como "toda atividade organizada, sistemática, educativa, realizada fora do espaço do sistema oficial" (COOMBS, AHMED, 1975, p.27, grifos nossos). Segundo Trilha (2008), esta modalidade de Educação surgiu no último terço do Século XX para suprir carências e deficiências presentes nas escolas. A ENF, por congregar metodologias e recursos diversos que, em algumas vezes, são distintos daqueles utilizados pelo professor em sala de aula e podem possibilitar a aprendizagem de temáticas específicas de modo a "sensibilizar" os aprendizes para modificar suas “atitudes”. De tal modo, que promovam mudanças comportamentais benéficas para a própria saúde e de outrem.

A ENF é "um espaço concreto de formação com a aprendizagem de saberes para a vida em coletivos" (GOHN, 2009, p.32, grifos nossos). Neste espaço, cabe a utilização de quaisquer metodologias educacionais, mesmo as provenientes da educação formal (TRILLA, 2008, p.42). Destacou Gohn (2006) que devido às contínuas mudanças, ao dinamismo e ao constante movimento da realidade nos espaços não formais, as metodologias de ensino utilizadas nestes locais assumem um alto grau de provisoriedade. Segundo esta autora, o aspecto metodológico é um dos pontos mais frágeis da ENF, justamente porque se origina da cultura de grupos e indivíduos, os métodos são originários da problematização da vida cotidiana, a partir de carências, obstáculos e necessidades destes mesmos grupos (GOHN, 2006, p. 31-32).

Ao considerar o espaço Sala de Espera, este artigo propõe uma ruptura como os modelos de investigação pautados em aspectos mentalistas mencionados até aqui. Assim, na contramão das orientações teóricas cognitivistas (ou mentalistas), que usualmente sustentam as investigações em espaços não formais de divulgação científica em Sala de Espera, esta pesquisa fundamentou-se na filosofia da ciência do comportamento denominada Behaviorismo Radical, de B.F. Skinner (1967; 1982); e em seus fundamentos metodológicos, com ênfase na Análise Aplicada do Comportamento, especificamente, a Avaliação Funcional Descritiva ou do inglês Functional Descriptive Assessment. Esta ferramenta é amplamente aplicada no tratamento de transtornos de comportamento autolesivos (CARSON, 2012; DIDDEN, 2007; CUNNINGHANM, O’NEILL, 2000; VOLLMER et al, 1995; LERMAN e IWATA, 1993), mas também com aplicação na formação de professores (GOMES, 2010; LOPES et al, 2009;:LPES, SPARVOLI, 2009) com resultados significativos na identificação de comportamentos-alvo e suas variáveis. 
O funcionalismo, como corrente de pensamento, rejeita quaisquer explicações simplesmente descritivas para explicar o comportamento baseando-se em sua topografia, pois, como tal, não explicariam o controle das funções (SKINNER, 1967). Este autor sustentou que, para ter propósito científico, a análise do comportamento deve ser realizada nos limites de uma ciência natural e estar fundamentada em eventos observáveis, pois é "exclusivamente em tais eventos que se deve confinar uma análise funcional” (idem, p.28, grifos nossos). Skinner (1967, p. 28) forneceu pistas na compreensão do que pode ser chamado de análise funcional ou causal, que busca estabelecer relações de causa e efeito no comportamento do organismo em interação com o ambiente. De outro modo, trata de buscar relações entre as variáveis externas das quais um dado comportamento é função. Busca estabelecer relações entre as variáveis dependentes (efeito, ou o comportamento propriamente dito) e as variáveis independentes do comportamento (causas, eventos que antecedem ou estão subsequentes à expressão de dado comportamento). Num levantamento recente, Beavers et al (2013), destacaram a ampliação do número de publicações que envolvem análises funcionais, salientaram que melhorar a eficiência das avaliações iniciais, manter o rigor e precisão é uma meta importante para o futuro da Análise Funcional.

As diferenças entre uma avaliação funcional e uma análise funcional podem estar circunscritas desta forma. A avaliação funcional refere-se a um conjunto de procedimentos na identificação de variáveis que podem atuar sobre o comportamento, seus eventos antecedentes e consequentes. A análise funcional busca identificar os determinantes de um comportamento-alvo, a manipulação experimental de eventos ambientais (GRESHAM, LAMBROS, 1998). Estes autores sugerem que a inserção de métodos distintos de coleta pode ampliar a confiabilidade dos dados obtidos. Desta forma, reconhece-se uma avaliação funcional pelo amplo conjunto de metodologias utilizadas na identificação de variáveis tanto no ambiente quanto no indivíduo - que potencialmente podem exercer influência direta no comportamento e suas fontes de controle (WATSON et al, 2011; VOLLMER et al, 2001, SASSO et al, 1992).

Diante do exposto questiona-se: o trabalho educativo realizado por profissionais da Saúde em espaços de educação não formal poderia sofrer modificações significativas a partir da realização de uma Avaliação Funcional Descritiva (AFD)? De outro modo, a prática educativa acerca do ensino de saúde em espaços não formais poderia sofrer modificações a 
partir do uso de uma ferramenta da Análise Aplicada do Comportamento, a AFD? De qualquer forma, é preciso compreender como se dá o arranjo de contingências na atuação dos profissionais de saúde (alguns ainda em formação inicial) no espaço da Sala de Espera e investigar como estes educadores "interpretam" seu "fazer educativo" em situações reais de ensino-aprendizagem. Nossa investigação buscou também fornecer pistas para a formação inicial do nutricionista, especialmente no que se refere ao planejamento de ações educativas e como estas são conduzidas nos espaços de espera por atendimento médico. Por fim, questionamos: a reprodução de modelos de discursos expositivos unidirecionais na Sala de Espera, isto é, apresentações do "tipo palestra" sem participação efetiva dos pacientes poderia ter implicações para os processos de ensino-aprendizagem decorrentes? Como possibilitar a participação dos pacientes de forma positiva na discussão? Quais fatores interferem a condução de atividades de ensino nestes locais?

Neste contexto, o presente estudo buscou investigar: (i) a prática educativa de uma graduanda do último ano do curso de Nutrição no espaço de educação não-formal denominado na literatura por 'Sala de Espera', em distintas Unidades de Estratégia de Saúde da Família; (ii) como a graduanda delimitou objetivos, estratégias de ensino e de avaliação, em três momentos distintos de interações com os pacientes. Além de (iii) verificar se um conjunto estruturado de passos com base numa ferramenta, a Avaliação Funcional Descritiva, poderia fornecer elementos para que a própria participante modificasse, em sua prática educativa, a interação com os pacientes em situação de espera.

\section{METODOLOGIA}

Trata-se de uma Pesquisa Qualitativa, na modalidade Delineamento de Estudo de Caso Único relatada na Ciência da Análise do Comportamento (ITTENBACH, LAWHEAD, 1997; BARKER, PISTRANG, ELLIOT, 1994). Esta modalidade de delineamento cuja característica principal é tratar os participantes individualmente tanto no que se refere ao próprio delineamento de pesquisa quanto no processamento dos dados (MATOS, 1990). Segundo a autora, o participante é exposto a determinadas condições no qual seu desempenho é mensurado de forma repetida, de modo que seja possível avaliar se existem ou não condições a serem manipuladas ambientalmente de forma a promover alterações nestas medidas. Matos e Tomanari (2002) sustentam que a ação de cada pessoa é produto único, fruto de uma série 
de fatores ou contingências nas quais a própria situação na qual a pessoa é exposta, somada a sua história passada e relações existentes entre as variáveis relevantes da situação presente atual. Como a história de vida de cada pessoa, segundo estes autores, é altamente idiossincrática e, ao somarem-se a ela diversidades de situações que cada um enfrenta, tornase improvável a comparação com outra pessoa. Delineamentos desta natureza só podem comparar os resultados do desempenho com o próprio indivíduo seja em outros momentos, situações ou condições, sobretudo porque qualquer diferença, se existir, é resultado da própria situação não resultado de uma variação individual (MATOS, TOMANARI, 2002).

A metodologia aqui adotada foi elaborada a partir de trabalhos com ênfase no Behaviorismo Radical de B.F. Skinner, por exemplo, Gomes (2010), Lopes Júnior et al (2009), Lopes Júnior e Sparvoli (2009) voltados à formação de professores. A proposta inicial deste estudo foi submetida e aprovada pelo Comitê de Ética em Pesquisa local (Resolução 466/12 CONEP). São participantes deste estudo: uma graduanda do último ano do Curso de Nutrição, doravante, Nicole ${ }^{1}$ e os pacientes em situação de espera (consideramos exclusivamente aqueles que participaram das interações promovidas). Todos os participantes assinaram um termo de consentimento livre e esclarecido (TCLE) na forma de convite que explicitou as condições de participação na pesquisa. A participante Nicole é aluna do último ano do curso de Nutrição e têm vinte e dois anos de idade. Foram realizadas seis entrevistas semiestruturadas com Nicole (Ver Quadro 1 abaixo), registros em videoteipe de três das Salas de Espera ${ }^{2}$ (SE1, SE2 e SE3) nas quais ocorreram interações da participante Nicole com os pacientes em situação de espera.

Antes do início da coleta, ocorreu um período de "ambientação" da participante à presença do pesquisador e ao uso da filmadora. Este registro foi desprezado das análises. Após o registro em vídeo das SE1 e SE2, procedeu-se a etapa de transcrição dos vídeos, da inserção de legendas com os programas Subtitle Workshop e AVI Recomp (versão 1.5.4), e análises das interações das SE1 e SE2 pelo pesquisador. Após esta etapa, a participante Nicole assistiu ao vídeo legendado da Sala de Espera 1 (SE1) e, ao término, o pesquisador apresentou um modelo

\footnotetext{
${ }^{1}$ Nome fictício.

${ }^{2}$ Vale destacar ao leitor a polissemia do uso da expressão "sala de espera" no contexto deste artigo. Esta pode referir-se tanto ao espaço físico onde as interações ocorreram quanto às interações de ensino organizadas pela participante. É comum as nutricionistas dizerem: “- Vou fazer aquela sala de espera." Momento em que se referem ao conjunto de ações educativas (e seus materiais de apoio) a serem disponibilizadas numa interação com pacientes em situação de espera.
} 
de Avaliação Funcional Descritiva (AFD) desta. Nesta mesma ocasião foi registrada uma entrevista, na qual a participante Nicole assistiu ao videoteipe da SE2 e foi convidada a realizar uma análise da mesma (registrada na Entrevista 4), a partir de exemplo apresentado pelo pesquisador. Depois de apresentada as considerações de Nicole sobre a SE2, o pesquisador apresentou uma AFD de aspectos considerados na SE2. O Quadro 1 abaixo apresenta uma síntese de toda metodologia utilizada neste estudo.

Quadro 1 - Síntese da Metodologia de coleta de dados utilizada neste estudo.

\begin{tabular}{|c|c|c|}
\hline \multirow{4}{*}{ 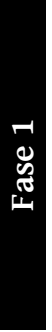 } & Entrevista 1 & $\begin{array}{l}\text { Escolhas da metodologia - temáticas abordadas } \\
\text { aspectos dos processos de ensino-aprendizagem nas interações com o } \\
\text { público. }\end{array}$ \\
\hline & Sala de Espera 1 (SE1) & $\begin{array}{l}\text { Registro em vídeo da SE1. Temática: "Quantas vezes você se alimenta por } \\
\text { dia?" }\end{array}$ \\
\hline & Sala de Espera 2 (SE2) & Registro em vídeo da SE2. Temática: “Temperos naturais”. \\
\hline & Entrevista 2 & $\begin{array}{l}\text { Delimitação de objetivos, estratégias e medidas de aprendizagem nas SE1 } \\
\text { e SE2. }\end{array}$ \\
\hline \multirow{2}{*}{ 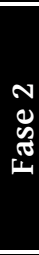 } & Entrevista 3 & $\begin{array}{l}\text { Nicole assistiu ao vídeo da SE1. Após a apresentação do video, foi } \\
\text { apresentada à participante Nicole uma Avaliação Funcional Descritiva } \\
\text { (AFD) elaborada pelo pesquisador da SE1. }\end{array}$ \\
\hline & Entrevista 4 & $\begin{array}{l}\text { Nicole assistiu ao vídeo da SE2 e fez uma proposta de análise do vídeo da } \\
\text { SE2 tendo como modelo a AFD apresentada pelo pesquisador. Uma análise } \\
\text { da SE2, elaborada pelo pesquisador, foi apresentada à participante Nicole. }\end{array}$ \\
\hline \multirow{3}{*}{ 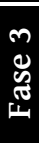 } & Sala de Espera 3 (SE3) & Registro em vídeo da SE3. Temática: Compra saudável. \\
\hline & Entrevista 5 & Delimitação de objetivos, estratégias e medidas de aprendizagem nas SE3. \\
\hline & Entrevista 6 & Entrevista final acerca da SE3. \\
\hline
\end{tabular}

Legenda: SE - sala de espera

Fonte: Os autores.

\section{RESULTADOS E DISCUSSÃO}

Para fins de apresentação e discussão dos resultados, eles foram apresentados abaixo atendendo a sequência de fases apresentadas na metodologia adotada explicitada no Quadro 1.

\section{Fase 1}

Na Fase 1, foi realizada a Entrevista 1, na qual a participante Nicole disse que trabalhou "muito pouco com o público" em situação de espera nos postos de saúde da cidade ao longo 
do curso de Nutrição. A participante Nicole acredita que os pacientes em situação de espera podem aprender conceitos científicos desde que "[...] forem explicados de maneira simples, eles prestam atenção e podem levar a informação transmitida por toda a sua vida" (Relato de Nicole). Quando se trata de ensinar as pessoas nos postos de saúde, Nicole relatou que as principais dificuldades estão voltadas ao barulho dentro da Unidade Básica de Saúde (UBS) e da falta de interesse de algumas pessoas ali presentes. O ensino nestes locais, segundo Nicole, pode ser favorecido pela presença dos painéis ilustrativos, pois “[...] quanto mais figuras, mais fácil chamar a atenção dos ouvintes" (Nicole). Ainda segundo a participante, as medidas de aprendizagem que ela consegue perceber nos pacientes são decorrentes de comentários e perguntas pertinentes ao assunto apresentado. De outro modo, Nicole obtém medidas das aprendizagens dos pacientes ao longo mesmo das interações da Sala de Espera, a partir de uma medida de consistência e pertinência das perguntas e comentários em relação aos conteúdos apresentados. Enquanto agente que opera no seu meio, Nicole elencou determinados aspectos que observou em eventos passados, isto é, em contatos anteriores com os pacientes em sala de espera. Fazemos o que fazemos em função do que ocorreu no passado e não do que ocorrerá (SKINNER, 1967). Assim, Nicole forneceu pistas de como compreendia as interações neste local: comportamento do paciente em "prestar atenção", de "desinteresse", de perturbadores de sua ação como o barulho típico do local e até mesmo de indício de aprendizagem ao realizar questionamentos pertinentes ao assunto. Observações presentes no ambiente e que estão diretamente ligadas à sua história pessoal (MATOS, 1990; MATOS, TOMANARI, 2002).

Ainda nesta Fase 1 e, após o período de ambientação, foram registradas duas salas de espera completas na quais ocorreram interações entre a participante Nicole e os pacientes em situação de espera. As temáticas foram: ‘Quantas vezes você se alimenta por dia?' (SE1) que versou acerca do fracionamento das refeições (ver Anexo A) e, sobre os 'temperos naturais' (SE2) que tratou do alto consumo de cloreto de sódio em produtos industrializados (ver Anexo B). Estas SE1 e SE2 ocorreram em dias distintos. Imediatamente após o término de cada uma delas, foi feito o registro em vídeo do roteiro de Entrevista 2, que buscou mapear como a participante Nicole delimitou os objetivos, estratégias de ensino e medidas de aprendizagem obtidas das interações com os pacientes. Os Quadros 2 e 3, abaixo, informam em síntese os principais resultados desta etapa. 
Quadro 2 - Delimitação de objetivos, estratégias de ensino e medidas aprendizagem na Sala de Espera 1.

\begin{tabular}{|c|c|}
\hline \multicolumn{2}{|c|}{ Síntese das respostas da estagiária Nicole - Entrevista 2/Sala de Espera 1 (SE1) } \\
\hline Tema/Título & Fracionamento das refeições/Quantas vezes você se alimenta por dia? \\
\hline Objetivos & $\begin{array}{l}\text { Transmitir as informações referentes ao número de refeições, que tem que ter no } \\
\text { mínimo de } 5 \text { a } 6 \text { refeições por dia. Investigar se as pessoas se alimentam } \\
\text { corretamente e se elas têm essas informações e (averiguar) como é a alimentação } \\
\text { delas. }\end{array}$ \\
\hline $\begin{array}{l}\text { Estratégias de } \\
\text { ensino }\end{array}$ & $\begin{array}{l}\text { Exposição oral. "Me apoiei no painel da Sala de Espera, para poder lembrar de tudo o que eu } \\
\text { precisava falar, e também fui perguntando para eles [os pacientes][...] se eles tinham essa } \\
\text { noção que tinha de se alimentar de } 5 \text { a } 6 \text { vezes ao dia" (Nicole) } \\
\text { "Passar a informação", com dicas dos tipos de alimentos para consumo. } \\
\text { Falar o que estava transcrito no painel. }\end{array}$ \\
\hline $\begin{array}{c}\text { Medidas de } \\
\text { Aprendizagem }\end{array}$ & $\begin{array}{l}\text { Leitura silenciosa do painel. } \\
\text { Adicionar condutas saudáveis ao cotidiano e melhorar os hábitos alimentares. } \\
\text { Interação com os pacientes. }\end{array}$ \\
\hline
\end{tabular}

Fonte: Os autores.

Na primeira aplicação do roteiro de Entrevista 2, referente à Sala de Espera 1 (SE1), na qual a participante Nicole informou os objetivos, estratégias de ensino e medidas de aprendizagem da SE1 com o título “Quantas vezes você se alimenta por dia?”. Verificou-se a relação funcional entre os aspectos mencionados por Nicole, por exemplo, quando Nicole delimitou como objetivo "transmitir informações" através de estratégias de ensino como "exposição oral", "passar informações" e "falar o painel". O mesmo ocorreu quando delimitou como objetivo "Investigar se as pessoas se alimentam corretamente e se tem tais informações", utilizando a estratégia "realizar perguntas". No entanto, inexistiu relação funcional com as medidas de aprendizagem passíveis de serem avaliadas pela participante Nicole, durante a ocorrência da SE1, justamente por estarem "debaixo da pele" dos pacientes, isto é, por se tratarem de medidas privadas (e não públicas) da aprendizagem (SKINNER, 1967; 1982) dos pacientes, por exemplo, "leitura silenciosa". Além de outras medidas que a participante Nicole não poderia avaliar diretamente - como, por exemplo, “Adicionar condutas saudáveis ao cotidiano e melhorar os hábitos alimentares" - por não estarem "ao alcance" de Nicole ou sob seu controle, ou por serem muito genéricas ou demasiadamente amplas, isto é, “a própria interação com os pacientes” - estas medidas por não descreverem propriamente quais aspectos da interação Nicole considerou ou mencionou. Entretanto, este aspecto ficou mais bem evidenciado com a fala de Nicole na qual se pode inferir que a participante reportou-se às participações orais dos pacientes: "Alguns gostam de interagir, outros não. É como dar aula, alguns alunos estão interessados, outros não. E com relação a isso, não há muito que possamos fazer. Então, aqueles que interagiram ou mesmo só prestaram atenção, interessados 
no tema, com certeza aproveitaram um pouco do que passei. Espero que tenham." (relato de Nicole sobre a SE1). Este relato de Nicole ao comparar a sala de espera com a sala de aula é consistente com o que a literatura traz sobre estar sob as contingências presentes na história de vida (MATOS, TOMANARI, 2002; MATOS, 1990; 1992).

Quadro 3 - Delimitação de objetivos, estratégias de ensino e medidas aprendizagem na Sala de Espera 2.

\begin{tabular}{|c|l|}
\hline \multicolumn{2}{|c|}{ Síntese das respostas da estagiária Nicole - Entrevista 2/Sala de Espera 2 (SE2) } \\
\hline Tema/Título & Uso do cloreto de sódio e produtos industrializados/Temperos Naturais \\
\hline \multirow{2}{*}{ objetivos } & $\begin{array}{l}\text { Investigar se as pessoas consomem ou não esses temperos naturais, investigar o } \\
\text { hábito alimentar dos pacientes. } \\
\text { Fornecer exemplos de temperos e verificar se os pacientes têm conhecimento deles. } \\
\text { Expor a questão do consumo exagerado de sódio e expor sobre os hábitos saudáveis } \\
\text { no preparo de alimentos e não usar os temperos industrializados. }\end{array}$ \\
\hline \multirow{2}{*}{$\begin{array}{c}\text { Estratégias de } \\
\text { ensino }\end{array}$} & $\begin{array}{l}\text { Fazer perguntas sobre o uso dos temperos naturais. } \\
\text { Falar da importância das pessoas fazerem uso dos temperos naturais. } \\
\text { Expor oralmente sobre a importância do uso desses temperos naturais. } \\
\text { Explicar, de modo reiterado, sobre a questão do sódio. Expor a ideia para eles. }\end{array}$ \\
\hline $\begin{array}{l}\text { Medidas de } \\
\text { Aprendizagem }\end{array}$ & $\begin{array}{l}\text { Participar oralmente com perguntas e comentários sobre a apresentação. } \\
\text { Fornecer exemplos do cotidiano relacionados ao tema exposto. } \\
\text { Saber relatar e fornecer relato da utilização caseira de temperos. } \\
\text { Fazer uso dos temperos naturais no cotidiano. } \\
\text { Saber da importância do uso de temperos naturais. } \\
\text { Possibilitar a mudança de hábitos antigos e inadequados no uso do cloreto de sódio } \\
\text { e } \\
\text { na preparação de temperos caseiros. } \\
\text { Saber explicar a relação entre o uso do sódio e suas quantidades em temperos } \\
\text { industrializados e saber explicar o porquê não utilizar os temperos prontos. } \\
\text { "Eu percebi que uma pessoa que no inicio não estava prestando muita atenção [...] } \\
\text { eujá havia falado sobre o sódio, mas eu retomei. Então é importante tentar fazer com que eles } \\
\text { absorvam aquele conteúdo". }\end{array}$ \\
\hline
\end{tabular}

Fonte: Os autores.

Na Entrevista 2, referente à Sala de Espera 2 (SE2) e registrada também ao término desta, com o título "Temperos Naturais", a participante Nicole indicou objetivos, estratégias de ensino e medidas de aprendizagem relacionadas à apresentação da SE2. A realização da SE1 e SE2 teve aproximadamente duas semanas de intervalo entre si. Podemos supor que a realização das entrevistas fez com que Nicole passasse a relatar de forma mais coerente os aspectos das interações de aprendizagem na SE2, conforme descrito em Gomes (2010), Lopes et al (2009) e Lopes e Sparvoli (2009). Assim, no Quadro 3 acima, foi evidenciado que ocorreu uma mudança consistente no modo como a participante Nicole correspondeu, funcionalmente, aspectos das aprendizagens dos pacientes, com os objetivos delimitados e estratégias de ensino utilizadas. Pode-se citar, por exemplo, quando Nicole delimita os 
objetivos: (i) "investigar o hábito alimentar dos pacientes", (ii) "investigar se as pessoas consomem os temperos naturais" e (iii) "verificar se os pacientes têm conhecimento [...]"; a participante delimitou como estratégia de ensino utilizada: (a) "fazer perguntas", (b) "falar da importância" e (c) "expor oralmente" e, das quais obteve como medidas de aprendizagem dos pacientes, a (a') "participação oral", com "fornecimento de exemplos" e (b') "fornecimento de relatos consistentes" com a temática, além de (c') "manifestar-se a respeito" e (d') "saber explicar a relação entre [...]". Contudo, apesar das relações feitas por Nicole na Entrevista 2 acima, ela própria estabeleceu objetivos de aprendizagem que se distanciaram de ações (ou "efeitos" conseguidos) nos pacientes e se aproximaram de ações da própria Nicole. De outro modo, pode-se inferir que a participante Nicole confundiu estratégias de ensino com objetivos a serem alcançados pelos pacientes com a apresentação da SE2. Alguns exemplos disto, isto é, da delimitação de ações da própria Nicole no alcance dos objetivos, pode-se elencar: "expor a questão do consumo exagerado de sódio", "expor sobre os hábitos saudáveis no preparo dos alimentos" " "fornecer exemplos de temperos e verificar se os pacientes têm conhecimentos deles". Neste mesmo sentido, isto é, da obtenção de medidas de aprendizagem dos pacientes em situação de espera durante a interação na SE2, a participante Nicole elenca como medidas "eventos privados" dos pacientes, isto é, medidas não públicas da aprendizagem e/ou públicas, mas que não estarão disponíveis para que Nicole possa diretamente avaliá-las. Por exemplo, "Fazer uso dos temperos naturais no cotidiano", "possibilitar a mudança de hábitos antigos e inadequados no uso do cloreto de sódio e na preparação de temperos caseiros". Como afirma Skinner (1967) e, apesar dos equívocos de Nicole, esta participante começou a estabelecer maior relação de funcionalidade entre os eventos ambientais dos quais operou quanto àqueles elementos constante de seu planejamento inicial da SE2.

A Fase 2 seguinte contou com a apresentação de uma Avaliação Funcional Descritiva (ver Quadro 4, abaixo) à participante Nicole das salas de espera SE1 e SE2 apresentadas (cf. Anexos A e B). 


\section{Fase 2}

Quadro 4 - Modelos de Avaliação Funcional Descritiva elaborados pelo pesquisador e apresentados à participante Nicole referente às salas de esperas SE1 e SE2.

\section{Sala de Espera 1 (SE1): Quantas vezes você se alimenta por dia?}

A participante forneceu condições para a ocorrência da participação oral dos pacientes (Nicole fez perguntas aos pacientes). Estas perguntas objetivaram identificar quantidades e frequência com que os pacientes se alimentavam ao longo de um dia. As perguntas elaboradas por Nicole fez com que muitos pacientes respondessem. No entanto, quando as perguntas trataram da importância do fracionamento da alimentação humana, Nicole fez questionamentos, contudo, que foi a própria Nicole quem imediatamente respondeu ou forneceu as respostas às perguntas. Com relação às perguntas elaboradas pela participante Nicole ao longo da Sala de Espera 1, Nicole ora fornece, ora não fornece adequadamente um tempo de espera para que os pacientes respondam às perguntas. Ao longo da apresentação, Nicole forneceu prontamente feedback após uma participação oral dos pacientes. Entretanto, apesar de fornecer tais feedbacks aos comentários e questionamentos dos pacientes, Nicole conduziu a exposição oral independentemente de tais participações. De outra forma, apesar de alta taxa de participação oral dos pacientes ao longo da SE1, a participante Nicole não fez uso dos conteúdos das falas dos pacientes para (a) reelaborar perguntas, (b) investigar hábitos alimentares e (c) incentivar a participação dos demais presentes; justamente porque quem forneceu exemplos de alimentos e de mal-estar decorrentes de longos períodos de jejum foi a própria participante Nicole. Deste modo, salientou-se que Nicole poderia problematizar as temáticas de modo a elaborar com antecedência as questões que melhor abordariam a temática. Outro aspecto salientado foi que Nicole ora fornece, ora não fornece o significado de termos para o público, o que pode sugerir que Nicole compreenda que as pessoas tenham domínio de termos como, por exemplo, o metabolismo. "Vai ajudar no metabolismo de cada um também" (Nicole) Nota: Nesta oportunidade, foram evidenciados os equívocos cometidos por Nicole acerca dos objetivos, estratégias e materiais didáticos elencados por Nicole.

\section{Sala de Espera 2 (SE2): Temperos Naturais}

A exemplo do que ocorreu na Sala de Espera anterior (SE1) possibilitou que os pacientes falassem, isto é, Nicole elaborou perguntas. Nicole forneceu os exemplos de temperos naturais e restringiu a participação dos pacientes à indicação se fazem ou não o uso de temperos industrializados e com qual frequência. Diante de uma participação oral de uma paciente que apresentou simultaneamente o uso de produtos naturais (urucum) e de temperos industrializados, Nicole indicou apenas a restrição do uso de produtos industrializados, seus teores de sódio e a relação com a hipertensão arterial. No entanto, não tratou do colorífico natural (urucum). Diante de uma pergunta que também tratou da conservação caseira de temperos naturais (por exemplo, alho, cebola, salsinha, cebolinha e coentro) em grandes quantidades de cloreto de sódio (sal de cozinha), pode-se inferir que Nicole não compreendeu ou não escutou a pergunta da paciente, sobretudo porque a participante Nicole forneceu uma resposta incongruente ou inconsistente que não correspondia diretamente ao que lhe fora perguntado. Assim como na SE1, durante a apresentação da SE2, e sem que os pacientes expressassem dúvidas, verificou-se que Nicole forneceu prontamente definições de palavras (por exemplo, "aditivo") e não forneceu de outras (por exemplo, "proteína"). Tal atitude impossibilitou Nicole de melhor investigar os conhecimentos que os pacientes já traziam consigo. Por exemplo, Nicole disse aos pacientes: "Aditivos, que são substâncias que eles põem para conservar o alimento por mais tempo" (Nicole) e "É importante vocês consumirem proteínas" (Nicole).

Fonte: Os autores.

Após a apresentação das avaliações funcionais descritivas (AFD), Nicole manifestou-se argumentando e justificando-se:

[...] Eu percebo que muitas pessoas acabam compreendendo o que estou falando, [Quando elas dizem: ] “- Ah, eu tive hipertensão, tenho que evitar o sódio” [...]. Tem que estar sempre explicando, retomando, aqueles termos que eles não conhecem muito bem. Trazer sempre para a linguagem deles. [...]. É difícil estar avaliando 
isso [o modo como os pacientes expressam a aprendizagem], mas no caso é a interação deles, é ele estar perguntando, falando do hábito dele, estar tirando dúvidas. Ou, às vezes, reparar nas expressões das pessoas, conforme eu lanço uma ideia, eles estarem reparando, ou comentando com a pessoa do lado. Esses gestos, se a gente observar, talvez responda essa questão [de aspectos relativos à demonstração de aprendizagem] (Relato da participante Nicole).

O relato de Nicole acima corrobora com o Modelo de Avaliação Funcional (AFD) apresentado anteriormente, porque o relato evidencia que a participante Nicole considera como medidas de compreensão alguns aspectos observáveis da aprendizagem; isto é, de ‘eventos públicos' e compartilhados pelos outros (SKINNER, 1967), quando, por exemplo, um paciente se manifesta oralmente na elaboração de um comentário ou dúvida pertinente. Como medida desta compreensão, Nicole também considera as aproximações que os pacientes fazem da linguagem acadêmica com a linguagem coloquial e vice-versa. Com relação ao sentido da palavra "interação", destacado anteriormente por Nicole, pode-se supor que Nicole considere como interação (e expressão das aprendizagens dos pacientes): “os comentários", "as perguntas", "falar com a pessoa ao lado" e "as expressões faciais dos rostos das pessoas" em situação de espera. No seu conjunto, eventos privados (prestar atenção, observar, reparar) e eventos públicos (falar com a pessoa ao lado, cochichar, fazer perguntas, expressões faciais ou comentários em voz alta) podem não fornecer adequadamente medidas para que Nicole possa avaliar seu contato com o público em situação de espera. Contudo, acredita-se que é com base na interação oral (comportamento verbal) com os pacientes, uma modalidade de evento público (SKINNER, 1967; KUBO, BOTOMÉ, 2001), que Nicole passe a melhor obter medidas de suas aprendizagens e compreensão dos temas que efetivamente ensinou.

\section{Fase 3}

Concluída a Fase 2, foi realizado o registro em videoteipe de uma terceira Sala de Espera (SE3) que tratou da temática alimentação saudável com o título "Compra saudável" (ver Anexo C). Após o registro desta SE3, foi realizado um novo encontro com Nicole no qual registramos duas entrevistas (Entrevistas 5 e 6). A Entrevista 5 buscou mapear na SE3 os objetivos, as estratégias de ensino e as medidas de aprendizagem - ou efeitos nos pacientes decorrentes das estratégias utilizadas - estabelecidos por Nicole nesta última Sala de Espera apresentada. O Quadro 5, abaixo, apresentou uma síntese desta entrevista. 
Quadro 5 - Delimitação de objetivos, estratégias de ensino e medidas aprendizagem na Sala de Espera 3.

\begin{tabular}{|c|c|}
\hline \multicolumn{2}{|r|}{ Síntese das respostas da estagiária Nicole - Entrevista 5/Sala de Espera 3 (SE3) } \\
\hline Tema/Título & Alimentação saudável/“Compra saudável” \\
\hline Objetivos & $\begin{array}{l}\text { Mostrar para as pessoas que há tanto 'alimentos saudáveis', como frutas, legumes e } \\
\text { verduras quanto 'produtos industrializados' como, por exemplo, chocolates, óleo. } \\
\text { Mostrar que há como substituir os alimentos industrializados pelos mais saudáveis, } \\
\text { frutas, verduras e legumes. } \\
\text { Incentivar a troca saudável de produtos industrializados por produtos naturais. } \\
\text { Relacionar qualidade nutricional com o preço e estabelecer comparações. } \\
\text { Fazer uma análise crítica do que a gente compra no mercado, dos nossos gastos no } \\
\text { mercado. }\end{array}$ \\
\hline $\begin{array}{c}\text { Estratégias de } \\
\text { ensino }\end{array}$ & $\begin{array}{l}\text { Exposição oral, elaborar perguntas, de forma a comparar os alimentos, falar um pouco } \\
\text { de preços, que eles podem variar em função do mercado e da marca. } \\
\text { Expor situação do cotidiano de uma compra regular. } \\
\text { Comparar produtos industrializados e produtos hortifrúti. } \\
\text { Expor sobre alimentos saudáveis em termos nutricionais e sua adequação à saúde. } \\
\text { Abordar questão financeira de alimentos saudáveis que têm menor custo. }\end{array}$ \\
\hline $\begin{array}{c}\text { Medidas de } \\
\text { Aprendizagem }\end{array}$ & $\begin{array}{l}\text { Comparar os alimentos e a questão do preço. "Deveriam observar que realmente os } \\
\text { produtos industrializados acabam saindo com um valor maior do que os produtos saudáveis: } \\
\text { as frutas, legumes e verduras. De modo, que eles criassem essa visão crítica em relação a preço } \\
\text { e qualidade do alimento". } \\
\text { Fazer relações entre os preços de produtos saudáveis naturais e produtos } \\
\text { industrializados. Pacientes disseram: "Nossa, muitas vezes uma fruta sai bem mais em } \\
\text { conta do que um chocolate, do que um pote de sorvete". } \\
\text { Participar oralmente: "Uma paciente disse que ela não toma refrigerante, só bebe água, e } \\
\text { que realmente a fruta sai mais em conta do que o próprio refrigerante [...]não tem muito o que } \\
\text { comentar. As pessoas acabam concordando e não tem muito o que discutir". }\end{array}$ \\
\hline
\end{tabular}

Fonte: Os autores.

Nesta Entrevista 5 foi evidenciado os limites da avaliação funcional apresentada à participante Nicole, pois nesta oportunidade Nicole explicitou objetivos que poderiam (e deveriam?), de modo simultâneo, ser alcançados por ela própria e pelos pacientes. Como exemplo, podem-se citar os objetivos "mostrar para as pessoas", "mostrar que há como substituir alimentos" e "relacionar a qualidade nutricional ao preço". Além de outros objetivos que foram delimitados para serem alcançados exclusivamente por Nicole, por exemplo, "incentivar a troca saudável de produtos" e "fazer uma análise crítica do que a gente compra no mercado". Acerca dos objetivos, diz Nicole: "O que eu percebi era que o objetivo seria alcançado dependendo se eles estivessem ou não entendendo o assunto. Eu vi que muitos estavam compreendendo, muitos não estavam prestando atenção, estavam preocupados, às vezes, com as consultas. Mas eu percebi que a maioria entendeu, porque é um tema fácil de trabalhar [...]" (Relato de Nicole).

No âmbito deste estudo e referencial teórico adotado, delimitar objetivos significa delimitar comportamentos - necessariamente passíveis de mensuração e de avaliação - dos 
repertórios dos aprendizes ao final da Sala de Espera. Comportamentos funcionalmente dependentes das estratégias de ensino proporcionadas ou condições de ensino arranjadas pela participante (ZANOTO, 2000; MATOS, TOMANARI, 2002; MATOS, 1992; 1990). As falas de Nicole na Entrevista 5 em muito se distanciaram de ações acerca da metodologia utilizada, porque elas não descrevem as ações realizadas pela graduanda ao longo da última Sala de Espera registrada, por exemplo, "Tentei aproximar o painel da realidade, do que a gente vê no supermercado" (Nicole). No sentido oposto desta fala, Nicole passou a melhor delimitar e descrever quais foram as estratégias de ensino efetivamente utilizadas, isto é, descreveu com pertinência as ações por ela organizadas ao longo da SE3 com a finalidade de alcançar os objetivos delimitados, funcionalmente dependente destes, na relação de funcionalidade e dependência entre processos de ensino-aprendizagem como propostos por Kubo e Botomé (2001). Este refinamento na descrição da participante também está atrelado à descrição dos efeitos obtidos nos pacientes em situação de espera ao longo da apresentação da SE3. Do mesmo modo e, se comparado especialmente à SE1, Nicole passou a relatar de forma pormenorizada, com melhor detalhamento as medidas de aprendizagem, isto é, características específicas dos comportamentos observados nos aprendizes durante a Sala de Espera (ver Quadro 5). Essa descrição, no entanto, não se limitou a 'eventos públicos' passíveis de observação direta, por exemplo, deveriam "observar a relação de preço", de modo, que "eles criassem essa visão crítica" (Nicole). Ou, mesmo quando Nicole menciona eventos públicos como medida de compreensão que não necessariamente evidenciam alguma medida de aprendizagem: "Eu vi as pessoas concordando com a cabeça, dizendo que 'sim'." (Nicole). "Eu vi que eles responderam, eles viram o painel, comentaram entre si" (Nicole). Neste mesmo sentido, afirma Nicole que, como efeito da interação que ela proporcionou, o paciente em espera demonstra que aprendeu: "É mais a pessoa concordar mesmo, ou acabar tirando alguma dúvida, como a paciente que disse: 'Eu não tomo refrigerante, não é bom, é muito mais caro"' (Relato de Nicole).

\section{Entrevista 6}

O último contato com a participante Nicole foi a Entrevista 6. Naquela oportunidade e, tendo em vista o delineamento adotado neste estudo com $\mathrm{N}=1$ no qual as ações do participante somente podem ser comparadas ao repertório dele próprio em outras situações (MATOS, TOMANARI, 2002; MATOS, 1990), Nicole foi convidada a comparar a SE3 que acabara 
de apresentar, com as salas de espera anteriores. Nicole admitiu que na SE3: "[...] eu aprendi a apresentar melhor a Sala de Espera" (Nicole). Apesar de visível as significativas e positivas mudanças que Nicole promoveu na condução da SE3, ela relacionou esta melhora principalmente a fatores extrínsecos aos seus próprios repertórios de ensino disponibilizados. Desta forma e, apesar da eficácia evidente da AFD, ao comparar a SE3 com as primeiras atividades em Sala de Espera, a participante Nicole atribuiu as modificações da SE3: (i) aos conteúdos da temática que é explicada aos pacientes, isto é, "O tipo de tema vai influenciar muito na participação do público [...] [quando a temática versou sobre o fracionamento de alimentos] foi muito mais fácil de ter participação" (Nicole); (ii) se o tema permite "discutir a realidade" e o "cotidiano das pessoas", por exemplo, “[...] é puxar um pouco a realidade para o painel [...] É passar o que está ali para puxar algumas questões (Nicole); (iii) ao uso da linguagem coloquial: "Com certeza, a linguagem é uma coisa a ser trabalhada se a gente está com um público idoso. Então, tem que falar em uma linguagem mais do dia-a-dia, mais do cotidiano, para que todos possam entender" (Nicole); (iv) à falta de conhecimento das pessoas (e, ao mesmo tempo, mudanças na forma como conduziu sua fala): "Então, muitos não têm um estudo muito bom [...] Quando você vai usar uma palavra 'mais cientifica' o legal é você citar a palavra e explicar o que ela é" (Nicole). De modo oposto, Nicole também atribuiu às mudanças a características intrínsecas da própria Nicole: "[...] Fiquei mais preocupada em falar o que tinha no painel do que me preocupar se minha voz estava dando para ouvir, se estava dando para ver o painel" (Nicole).

Tanto na Fase 3 quanto na SE3, Nicole passou a nomear objetivos, estratégias de ensino e medidas de avaliação com maior propriedade e clareza no que se refere à relação de funcionalidade entre estes. Especificamente no conjunto de comportamentos de Nicole na SE3, ela interagiu de forma a fornecer um maior tempo de espera, isto é, interrompeu sua fala para que os pacientes pudessem se manifestar oralmente às perguntas que fez, conduziu sua fala "de forma a aproveitar" partes das falas dos pacientes na sua exposição, atendeu as dúvidas dos pacientes, de todos eles. Por fim, agiu de forma contingente com as demandas da sala de espera (MATOS, TOMANARI, 2002; MATOS, 1990; 1992; SASSO et al, 1992, SKINNER, 1967). 


\section{CONSIDERAÇÕES FINAIS}

Nossos objetivos consistiram em: (a) investigar a prática educativa da participante Nicole, graduanda do curso de Nutrição, em salas de espera na divulgação científica de temas de saúde; (b) averiguar como ela delimitava objetivos, estratégias de ensino e formas de avaliação da aprendizagem; (c) verificar se uma ferramenta da Análise Aplicada do Comportamento (SKINNER, 1967/1982), a Avaliação Funcional Descritiva (AFD) forneceria elementos para que Nicole realizasse alterações na forma como ela própria interagia com os pacientes-aprendizes. As mudanças apresentadas por Nicole são consistentes com dados presentes na literatura no contexto da Educação Formal em Ciências (cf. GOMES, 2010, LOPES JÚNIOR et al, 2009; LOPES JÚNIOR, SPARVOLI, 2009). A principal contribuição desta pesquisa aos nutricionistas em formação é a possibilidade de uso do vídeo como forma de autocontrole dos comportamentos de ensino em espaços de divulgação científica. Quais foram os efeitos das ações de Nicole no contexto das três salas de espera? Os pacientes realmente aprenderam o que ela pretendia ensinar? De fato, sobre o processo de ensinar, como salientam Kubo e Botomé (2001):

Ensinar define-se por obter aprendizagem do aluno e não pela intenção (ou objetivo) do professor ou por uma descrição do que ele faz em sala de aula. A relação entre o que o professor faz e a efetiva aprendizagem do aluno é o que, mais apropriadamente, pode ser chamado de ensinar. Nesse sentido, ensinar é o nome da relação entre o que um professor faz e a aprendizagem de um aluno (KUBO, BOTOMÉ, 2001, s/p., grifos nossos).

Ao atuar como educadores de um espaço não formal, os profissionais da saúde podem, com ajuda da Análise Aplicada do Comportamento proposta por Skinner (1967/1982), em especial a Avaliação Funcional Descritiva (AFD), melhor compreender aspectos e condutas presentes nos aprendizes e em seus mestres, de modo que estas sejam de interesse para o planejamento, organização das interações e mesmo a avaliações das aprendizagens que desenvolvem nestes espaços.

Percebemos que Nicole inseriu modificações significativas na forma como conduziu a sala de espera final (SE3) e, depois, como descreveu as interações ocorridas entre ela e os pacientes. A AFD forneceu condições para que a participante modificasse pontualmente aspectos de seu repertório de ensino ao longo da exposição da última Sala de Espera (SE3). Apesar de Nicole reconhecer que aprendeu a apresentar melhor a Sala de Espera, ela impôs 
como determinantes desta mudança: à facilidade do tema apresentado e a relação deste com a vida cotidiana das pessoas, ao uso da linguagem coloquial, à falta de conhecimento e escolarização dos pacientes. Em conjunto, segundo o relato de Nicole, estas características foram responsáveis pelas modificações no modo como ela conduziu o tema da SE3. Para finalizar vale destacar a fala da pesquisadora Zanotto que afirmou “(...) quem ensina, o faz para que alguém aprenda alguma coisa de modo eficiente (...) [e] deve ficar sob o controle do que quer ensinar, de quem está sendo ensinado e das condições disponíveis" (ZANOTTO, 2000, p. 42, grifos nossos).

\section{REFERÊNCIAS BIBLIOGRÁFICAS}

BARKER, C.; PISTRANG, N.; ELLIOT, R.; Research methods in clinical and counseling psychology. Chichester, Inglaterra: John Wiley \& Sons, 1994.

CARSON, S.D.; Social validity, acceptability, and utility of behavior mapping: a simple functional behavior assessment.2012. 143f.Doctor of Philosophy. School of Education, Indiana University,Ann Arbor, 2012.

COOMBS, P.H.; AHMED, M. La lucha contra la pobreza rural: El aporte de la educación no formal. Madrid: Editorial Tecnos, $1975.371 \mathrm{p}$.

DIDDEN, R. Functional analysis methodology in developmental disabilities. In: STURMEY, P. (Ed), Functional analysis in clinical treatment, Burlington: Academic, 2007,p. 65-68.

GOHN, M.G. Educação não-formal, educador(a) social e projetos sociais de inclusão social. Meta: Avaliação, Rio de Janeiro, v. 1, n. 1, p. 28-43, jan./abr. 2009.

. Educação nãoformal e cultura política: impactos sobre o associativismo do terceiro setor. 4. ${ }^{\mathrm{a}}$ Ed. São Paulo: Cortez, 2008, 120p.

Educação não-formal, participação da sociedade civil e estruturas colegiadas nas escolas. Ensaio:

aval.pol.públ.Educ., Rio de Janeiro , v. 14, n. 50, mar. 2006.

Educação não-formal na pedagogia social. In: I CONGRESSO INTERNACIONAL DE PEDAGOGIA SOCIAL, n. 1, 2006, São Paulo. Proceedings online... Faculdade de Educação, São Paulo: Ed. Universidade de São Paulo, [2006] Em web:

<http://www.proceedings.scielo.br/scielo.php?script=sci_arttext\&pid=MSC0000000092006000100034\&lng=en \&nrm=abn>. Acesso em: 13 mai. 2014.

GOMES, P.C. et al. Investigando a aprendizagem em espaços não-formais: o caso da educação em saúde. Em: Encontro Nacional de Pesquisa em Educação e em Ciências - ENPEC, 9., Águas de Lindóia. Atas do IX Encontro.... ABRAPEC, 1-8, Nov, 2013. 1-8, Disponível em: <http://www.nutes.ufrj.br/abrapec/ixenpec/atas/resumos/R1659-1.pdf>, Acesso: dez/2013.

GOMES, P.C. Ensino e aprendizagem de avaliação funcional descritiva na atuação profissional de professores de ciências no ensino fundamental. 2010. 269f. Tese de Doutorado (Doutorado em Educação Para a Ciência). Faculdade de Ciências. Universidade Estadual Paulista Júlio de Mesquita Filho, Bauru. 
GRESHAM, F.M.; LAMBROS, K.M.; Behavior and Functional Assessment. In: WATSON, T.S.; GRESHAM, F.M.(Eds.) Handbook of Child Behavior Therapy. New York: Plenum Press, 1998,p. 3-40.

ITTENBACH, R. F., e LAWHEAD, W. F.; Historical and Philosophical Foundations of Single-Case Research. Em: R. D. Franklin, D. B. Allison, e B. S. Gorman (Eds.). Design and analysis of single-case research. Mahwah, NJ: Lawrence Erlbaum, 1997, p. 13-39.

KUBO, Olga Mitsue; BOTOMÉ, Sílvio Paulo. Ensino-aprendizagem: uma interação entre dois processos comportamentais. Interação em Psicologia, Curitiba, v. 5, dez. 2001. Disponível em: <

https://revistas.ufpr.br/psicologia/article/view/3321 >. Acesso em: 01 maio 2017.

LOPES JÚNIOR, J; et al. O ensino de ciências nas séries iniciais: desenvolvimento de aprendizagens profissionais no âmbito da formação de professores. Em: NARDI, R. (org). Ensino de ciências e matemática I: temas sobre a formação de professores. 1. ․ㅡ. Ed. São Paulo: Cultura Acadêmica, v.1, Cap. 11, 2009, p. 179-191. Disponível em: < http://static.scielo.org/scielobooks/g5q2h/pdf/nardi-9788579830044.pdf > Acesso em: out 2013.

LOPES JÚNIOR, J.; SPARVOLI, D.A.P. Avaliação de Interações entre Professor e Alunos na Educação Matemática: ensino e aprendizagem de recursos pedagógicos. Bolema, Rio Claro - SP, v.22, n. 33, p.141-168, 2009.

MATOS, M. A. Controle experimental e controle estatístico: A filosofia do caso único na pesquisa comportamental. Ciência e Cultura, 42, 585-592, 1990.

MATOS, M.A. Análise de contingências no aprender e no ensinar. Em: ALENCAR, E.S. (Org.) Novas contribuições da psicologia aos processos de ensino e aprendizagem. 1. ㄹ Ed. São Paulo: Cortez, v. 1, 1992, p. 141-165.

MATOS, M. A.; TOMANARI, G. Y. A Análise do Comportamento no laboratório didático. São Paulo: Manole, 2002, 135p.

MEC. BRASIL. Ministério da Educação. Conselho Nacional de Educação. Institui diretrizes curriculares nacionais do curso de graduação em nutrição. Resolução CNE/CES 5, de 7 de novembro de 2001. Diário Oficial da União. 2001; nov 9, Seção 1, p.39.

SASSO G. M., RETMERS T. M., COOPER L. J., WACKER D., BERG W., STEEGE M., et al. (1992). Use of descriptive and experimental analysis to identify the function properties of aberrant behavior in school settings. J. Appl. Behav. Anal. 25, 1992. Em web: <https://www.ncbi.nlm.nih.gov/pmc/articles/PMC1279766/pdf/jaba000180058.pdf > Acesso em 12.10.2015.

SKINNER, B.F. Sobre o behaviorismo. São Paulo: Cultrix, 1982, 216p.

Ciência e Comportamento Humano, Brasília: Ed. UnB/FUNBEC, 1967, 252p. (edição original de 1953).

TEIXEIRA, E.R.; VELOSO, R.C. O grupo em Sala de Espera: O território de práticas e representações em saúde. Texto Contexto Enferm, Florianópolis, v. 15, n.2, p.320-325, Abr/Jun, 2006.

TRILLA, J. A educação não formal. Em: ARANTES, V.A. (Org.) Educação formal e não formal: pontos e contrapontos. São Paulo: Summus, 2008, 167p.

VOLLMER, T.R.; BORRERO, J.C.; WRIGHT, C.S.; VAN CAMP, C.; LALLI, J.S.; Identifying possible contingencies during descriptive analyses of severe behavior disorders. Journal of Applied Behavior Analysis, v.34, n.3, p.269-287, 2001.

WATSON, T.S.; STEEGE, M.W.; WATSON, T.S.; Functional Assessment of Behavior. In: BRAY, M. A.; KEHLE, T.J.; (Ed.) The Oxford Handbook of School Psychology, Oxford: Oxford University Press, 2011, p.187-204.

ZANOTTO, M.L.B. Formação de professores: a contribuição da análise do comportamento. São Paulo: FAPESP/EDUC, 2000, p.183. 
Anexo A - Síntese da Sala de Espera 1 (SE1) com a temática "Quantas vezes você se alimenta por dia"

Síntese das ações de Nicole e dos pacientes participantes

(1) Nicole entra no ambiente de espera dos pacientes trajando um jaleco branco. Afixa um cartaz com o título "Quantas vezes você se alimenta por dia".

(2) Nicole cumprimenta os pacientes e se apresenta dizendo o seu nome, a área e o nome do curso e o nome da Instituição de Ensino Superior onde estuda.

(3) Nicole inicia sua exposição fazendo questionamentos: "Alguém quer começar falando como se alimenta em casa? Se faz várias refeições? Se faz duas refeições? [...] Como vocês se alimentam?”

(4) Pacientes respondem as quantidades.

(5) Nicole faz novos questionamentos: “Alguém come bastante? Assim, várias vezes? Ou comem uma ou duas vezes só?"

(6) Paciente novamente responde.

(7) P3 questiona: "A senhora come bastante? Mais ou menos, quantas vezes por dia?".

(8) Paciente responde "Eu acordo e como. Depois tomo café às $10 \mathrm{~h}$ ".

(9) P3 prossegue questionando: “A senhora come, depois toma café às 10h, e depois? Só janta? Assim, três refeições por dia? A senhora não sente fome?”

(10) A paciente gesticula com a cabeça dizendo que não, isto é, que ela não sente fome.

(11) Nicole diz que são pouquíssimas refeições. Salienta que o indicado é pelo menos cinco ou seis refeições por dia e explica quais são elas.

(12) Nicole prossegue e questiona: “Então, o legal é comer várias vezes ao dia, por quê?”

(13) Pacientes sentados em silêncio.

(14) Em seguida responde à própria pergunta: "Porque comendo várias vezes ao dia irá auxiliar no metabolismo de cada um. A pessoa vai se sentir melhor, mais disposta, o intestino dela irá funcionar melhor, ela irá ter mais energia para fazer as atividades do dia. Por isso que o café da manhã é muito importante. E tem muita gente que não toma o café da manha, quem aqui não toma o café da manha? De jeito nenhum?"

(15) Uma paciente diz que não toma café da manhã e que não consegue se alimentar pela manhã.

(16) Nicole faz questionamentos: "Não toma? Não consegue comer nada?... Mais alguém?"

(17) Outros pacientes dizem que não se alimentam no café da manhã.

(18) Em seguida, Nicole explica a importância de fazer a primeira refeição do dia e sua relação com o período de jejum e a queima de energia. Fornece exemplos de alimentos saudáveis e não saudáveis que se pode comer no café da manhã: "Leite, suco de frutas, uma fruta, o pão francês, pão de leite ou um cereal, que seria um cereal integral [...] aveia com fruta [...] um pedaço de bolo simples, não aqueles bolos de festa, cheios de gorduras e açúcar já cedo".

(19) Pacientes sentados em silêncio.

(20) Nicole expõe oralmente sobre a importância de se fazer pequenas refeições ou 'lanches' nos intervalos das refeições principais. Nicole fornece exemplos de alimentos a ser consumidos nos horários de lanches: "uma vitamina de frutas, um iogurte, uma fruta, uma barrinha de cereal, um pedaço de queijo branco".

(21) Pacientes sentados em silêncio.

(22) Nicole salienta a importância de fazer várias refeições ao longo do dia e aponta o mural.

(23) Nicole expõe sobre a importância de comer as frutas da estação e sua relação com os preços.

(24) Nicole fornece exemplos de bem estar do corpo e sua relação com o fracionamento das refeições. Nicole fornece exemplos de sintomas de mal estar físico e de sua relação com a alimentação não fracionada.

(25) Nicole pergunta o nome de uma paciente que tinha dito anteriormente que não conseguia alimentar-se pela manhã e que comia duas vezes ao dia.

(26) A paciente responde.

(27) Nicole repete o nome da paciente e diz que ela deve comer mais vezes ao dia. Disse à paciente que deveria relacionar o fracionamento com a sensação de disposição no dia-a-dia.

(28) Nicole questiona se alguém tinha alguma dúvida ou comentário a fazer.

(29) Uma paciente levanta a mão e diz que tinha uma. O paciente disse: "Eu tenho muita tontura e dor de cabeça, será que é por causa disso?"

(30) Nicole responde: “- Pode ser que seja, pode ser. A senhora come quantas vezes ao dia?"

(31) Paciente responde: “- Eu almoço. Lá pelas 16 horas, bebo leite [...] duas ou três refeições ao dia”

(32) Nicole questiona se a paciente não toma o café da manhã.

(33) A paciente diz que não toma.

(34) Nicole novamente responde à paciente relacionando a energia presente nos alimentos e às necessidades calóricas do organismo. Nicole diz a paciente que a dor de cabeça, o mal-estar e a "fraqueza" sejam decorrentes de longos períodos em jejum. 
(35) A paciente concorda com Nicole gesticulando com a cabeça.

(36) Nicole finaliza dizendo: "Tenta fazer mais refeições ao dia e compara se melhora ou não, certo?"

(37) A paciente responde dizendo que vai tentar fazer isso.

(38) Nicole diz que o mal-estar da paciente pode sim ter relação com o não fracionamento da alimentação e ainda salientou a importância de tomar bastante água: " - Vai ajudar no metabolismo de cada um também”.

(39) Nicole questiona se mais alguém gostaria de falar alguma coisa e uma paciente levanta a mão.

(40) A paciente diz: "Eu não sinto um pingo de fome".

(41) Nicole questiona se ela não sente mal-estar.

(42) A paciente diz que não. Alega que viaja bastante e diz: "Só o café puro. Tem vez que nem o café puro, eu não tomo. Vou lá e chego... Tem vez que é tão longe que já é hora de almoçar".

(43) Nicole questiona o nome da paciente e utiliza o seu exemplo para destacar a importância de estar estimulando o organismo a se alimentar e como isso contribui com a saúde.

(44) A paciente insiste: “- Mesmo sem fome?”

(45) Nicole finaliza dizendo “- Mesmo sem fome, é importante. Não pode deixar de se alimentar [...] muito tempo em jejum não é interessante para ninguém”.

(46) Questiona se mais alguém gostaria de acrescentar algo. Nenhum paciente se manifestou. Nicole agradeceu e encerrou a apresentação de Sala de Espera.

Anexo B - Síntese da Sala de Espera 2 (SE2) com a temática "Temperos naturais"

Síntese das ações de Nicole e dos pacientes participantes

(1) Nicole entra no ambiente de espera dos pacientes e afixa um cartaz com o título "Temperos naturais".

(2) Inicia cumprimentando a todos e se identificando como estagiária da Nutrição e diz o nome da Instituição de ensino superior que cursa.

(3) Faz questionamento se algum dos presentes fazia uso de temperos naturais. Forneceu exemplos: alho, cebola, coentro, salsa. Falou do uso para temperar os alimentos em seu preparo.

(4) Uma paciente levanta a mão e diz que faz uso de alho e cebola.

(5) Nicole repete a resposta da paciente: “- Alho e cebola?" e questiona: "A senhora não coloca sal?"

(6) Paciente fiz que não. Diz que faz o tempero e coloca em potes na geladeira e diz: "- Eu gosto de salsinha”.

(7) Nicole questiona se os pacientes usam "sazon" (tempero industrializado) e "aquelas coisas" (condimentos industrializados).

(8) Paciente diz que coloca temperos industrializados na carne.

(9) Nicole questiona se o uso é contínuo ou se eventualmente tempera a carne com o tempero industrializado.

(10) A paciente diz: “- Sempre”.

(11) Nicole questiona se mais alguém quer falar e uma paciente levanta a mão.

(12) A paciente diz que usa "Sal, cebola, salsinha..."

(13) Nicole diz que entendeu e questiona se alguém mais gostaria de falar algo.

(14) Paciente não se manifestam.

(15) Nicole faz uma exposição oral de tipos de temperos naturais que dão sabor as preparações, destacando que são mais saudáveis que os temperos industrializados.

(16) Nicole questiona o nome de uma paciente.

(17) A paciente diz o nome.

(18) Nicole repete o nome da paciente. Nicole diz alguns exemplos de temperos industrializados fornecendo exemplos de nomes (caldo knorr, sazon, etc.). Nicole diz que os temperos prontos não são interessantes na alimentação porque eles possuem alto teor de sal em sua composição.

(19) Nicole expõe oralmente sobre a relação entre as quantidades de sódio nos temperos prontos e sua relação com as necessidades diárias do ser humano. Nicole expôs aos pacientes sobre a utilização de aditivos nestes temperos, como os corantes e substâncias para conservar o produto.

(20) Uma paciente diz que só usa tempero pronto e aqueles que dão cor ao arroz, como urucum.

(21) Nicole salienta para que os pacientes mudem seus hábitos com relação aos produtos industrializados, dos teores de sódio e sua relação com a hipertensão arterial.

(22) Uma paciente diz que faz tempero caseiro e o conserva com muito sal. Paciente questiona Nicole se tem problema.

(23) Nicole não responde à paciente.

(24) Nicole novamente destaca os cuidados com o uso em excesso do sal de cozinha principalmente para os hipertensos. Nicole diz à paciente a qual fez a última pergunta: "Esses aqui são os temperos naturais [e aponta o quadro] A gente tem o orégano [...] o hortelã, a salsa, manjericão o alecrim e a babosa, a salsicha, cheiro-verde". 
(25) Nicole fornece exemplos de usos dos temperos naturais, por exemplo, "Nos ovos, pode estar utilizando pimenta, sal, alho. Nos peixes podemos usar alho e coentro".

(26) Nicole destaca a importância de se cultivar os próprios temperos em casa.

(27) Pacientes comentam entre si [inaudível].

(28) Uma paciente diz que já faz o cultivo dos temperos em sua casa.

(29) Pacientes continuam comentando.

(30) Uma paciente comentou que gosta de utilizar os temperos prontos em seus pratos.

(31) Nicole novamente fala que eles têm muito sódio na composição, que é muito perigoso para pessoas com hipertensão, das substâncias conservantes, dos corantes artificiais e que seu consumo não traz nenhum benefício ao organismo.

(32) Nicole fala para que os pacientes olhem a tabela nutricional nos rótulos dos alimentos e confiram o teor de sódio.

(33) Nicole finaliza questionando se alguém tinha alguma dúvida ou comentário.

(34) Pacientes permanecem em silêncio.

(35) Nicole agradece e encerra a sala de espera dizendo que está a disposição para esclarecer.

Anexo C - Síntese da Sala de Espera 3 (SE3) com a temática "Compra saudável"

$$
\text { SÍNTESE DA APRESENTAÇÃO INTITULADA 'COMPRA SAUDÁVEL' }
$$

(1) Nicole entra na sala de espera, apresenta-se dizendo seu nome, curso que frequenta e o nome da instituição de ensino superior onde estuda. Informa aos pacientes que fará uma conversa com eles sobre o tema "compra saudável".

(2) Inicia fazendo questionamentos aos pacientes: "Alguém aqui de vocês costuma ir fazer compras no mercado? É outra pessoa quem faz?"

(3) Alguns pacientes respondem "sim". Outros permanecem em silêncio.

(4) Nicole faz uma exposição oral sobre produtos "mais caros" e "menos caros" tanto industrializados quanto na parte de 'hortifruti'. Nicole passa a apresentar produtos industrializados e produtos hortifruti e passa a fazer comparações entre os preços dos produtos. Por exemplo, "Um Litro de óleo custa $R \$ 2,60$. Com esse valor eu consigo comprar dois maços de Couve Manteiga. É uma troca mais saudável". Nicole apresenta outras três comparações de preços e prossegue sua exposição oral.

(5) Nicole questiona: "Quem bebe Coca-Cola?"

(6) Pacientes respondem que bebem. Outros respondem que não bebem.

(7) Nicole questiona aos pacientes que não bebem coca-cola se eles tomam suco natural.

(8) Pacientes respondem que não bebem suco. Somente água.

(9) Nicole relaciona que o preço de uma coca-cola de dois litros equivale a compra de vinte e duas laranjas que podem produzir aproximadamente dois litros de suco. Nicole salienta que o suco sai mais "em conta" ou mais barato.

(10) Nicole faz a mesma comparação entre caixa de bombons e maçãs.

(11) Nicole expõe sobre a importância de consumir "frutas da estação", de ir às hortas comunitárias. Nicole questiona aos pacientes: "Quem aqui tem o costume de ir a hortas comunitárias?"

(12) Novamente os pacientes respondem que sim e outros que não. Alguns dizem que vão às vezes.

(13) Nicole faz questionamentos aos pacientes: "Vai de vez em quando? Alguém mais vai à alguma horta comunitária? Conhece alguma aqui na cidade? Conhece? Não conhece?"

(14) Pacientes respondem ao mesmo tempo. Acenam que sim com a cabeça.

(15) Nicole reitera a importância da compra em hortas comunitárias, das "frutas de época" e de que é mais saudável comprar produtos "hortifruti" é mais barato e saudável que optar por produtos industrializados.

(16) Nicole encerra a sala de espera questionando se os pacientes tinham alguma dúvida ou se queriam fazer algum comentário.

(17) Pacientes sentados e não se manifestam.

(18) Nicole agradece a oportunidade e encerra agradecendo. 